\title{
Tumor Bed Boost Integration during Whole Breast Radiotherapy: A Review of the Current Evidence
}

\author{
Pierfrancesco Franco $^{a}$ Domenico Cante ${ }^{b}$ Piera Sciacero ${ }^{b}$ Giuseppe Girelli ${ }^{b}$ \\ Maria Rosa La Porta ${ }^{b}$ Umberto Ricardi ${ }^{a}$ \\ a Department of Oncology, Radiation Oncology, University of Torino, Turin, Italy; \\ ${ }^{b}$ Radiation Oncology Department, Ivrea Community Hospital, ASLTO4, Ivrea, Italy
}

\section{Keywords}

Adjuvant whole breast radiotherapy .

Concomitant boost - IMRT · IGRT - Hypofractionation .

Simultaneous integrated boost . Breast cancer

\section{Summary}

Radiation therapy delivered with hypofractionation, which involves the delivery of a higher dose per fraction in fewer fractions (generally with a lower total nominal dose) over a shorter overall treatment time, is an established therapeutic option at least for a selected group of early breast cancer patients after breast-conserving surgery. Optimal delivery of the tumor bed boost dose in terms of timing, fractionation, and total dose whenever a hypofractionated schedule is employed has yet to be established. We herein present a review of the current evidence on the role of boost integration in whole breast radiotherapy.

\section{Introduction}

Combining breast-conserving surgery (BCS) and radiation therapy (RT) is a mainstay option in the multimodality treatment of breast cancer with optimal long-term local control, mild toxicity, good cosmetic outcome, and survival rates comparable to mastectomy [1]. Adjuvant whole breast radiotherapy (WBRT) yields a local failure rate of $3-15 \%$ depending on the patient cohort and variables such as intrinsic risk factors, type of surgery, and followup time [2]. However, in recent years, substantial improvements in the fields of early diagnosis, clinical selection, surgery, RT technol- ogy, and systemic treatments have led to an increase in local control, with higher rates than those observed in early randomized trials [3]. It has been demonstrated that good local control translates into improved overall survival (OS) [4]. The rationale for delivering an adjunctive radiation dose boosting the lumpectomy cavity is derived from several considerations: First, the radiobiological observation of a dose-response relationship for breast cancer; second, the pathological evidence of a higher microscopic tumor burden in proximity to the site of lumpectomy; and third, the clinical observation of the local pattern of failure close to the primary tumor location [5-7]. Randomized phase III trials exploring the role of boosting the tumor bed demonstrated a relative reduction in local failure in the range of $20-50 \%$, depending on risk factors of the patient cluster analyzed [2]. However, in spite of this substantial clinical benefit, in several countries there has been a tendency to omit adjuvant WBRT after BCS, especially in women over 70-80 years, but also in younger patients, maybe due to the extended overall treatment time using a conventionally fractionated schedule and sequential boost approach [8]. Hypofractionation (HF) (delivery of a larger dose per fraction in shorter overall time) and concurrent boost (delivery of a synchronous adjunctive dose to the tumor bed) represent a useful option to optimize treatment both for patients and healthcare providers [9].

\section{Boosting the Tumor Bed \\ Local Control and Cosmetic Outcome}

A boost dose to the lumpectomy cavity can be delivered with external photon beam RT, external electron beam RT, and highdose brachytherapy employing an after-loading system administered either intraoperatively or after WBRT. Boosting the tumor

\section{KARGER \\ Fax +497614520714

\section{(c) 2015 S. Karger GmbH, Freiburg}

$1661-3791 / 15 / 0101-0044 \$ 39.50 / 0$
Domenico Cante, MD 
bed in addition to WBRT has been shown to improve local control with mild side effects and acceptable cosmetic outcome in several randomized phase III trials. The absolute gain ranges from 1 to $40 \%$, while the relative local failure reduction varies from 20 to $50 \%$ depending on the characteristics of the cohort [2]. The EORTC 'Boost Versus No Boost' trial (22881/10882) randomized 5,318 patients (after clear-margin BCS) to receive conventionally fractionated WBRT (50 Gy/25 fractions (fr)) with either an additional $16 \mathrm{~Gy} / 8$ fr boost (or 15 Gy low-dose rate brachytherapy) or not [10]. The boost dose provided a benefit in terms of local failure ( 6.2 vs. $10.2 \%$ at 10 years; $\mathrm{p}<0.0001$ ), predominantly in younger patients ( $<40$ years), with a hazard ratio of local recurrence of 0.59 [11]. However, the $16 \mathrm{~Gy}$ boost group had worse cosmetic results (photographic assessment with a subjective panel and objective measurements) than the no boost group, in terms of 10 -year severe fibrosis (4.4 vs. 1.6\%) [11]. In the Lyon trial, 1,024 T1-T2 breast cancer patients were randomized to receive a hypofractionated (50 Gy; 2.5 Gy daily) WBRT schedule (50 Gy/20 fr; 2.5 Gy/daily) with either an additional 10 Gy hypofractionated sequential boost (10 Gy/4 fr; 2.5 Gy daily) or no boost [12]. The boost dose resulted in a lower local recurrence rate ( 3.6 vs. $4.5 \%$; $<0.05)$ and a higher rate of G1-G2 telangiectasia (12.4 vs. $5.9 \%$ ) but no difference in cosmetic self-scoring and scoring results obtained by the physician [12]. The Budapest trial, reporting on 207 patients (1/3 of the planned study group of 604 patients), compared a boost strategy (16 Gy/8 fr with electrons or 12-14.25 Gy with high-dose rate brachytherapy) after conventionally fractionated WBRT (50 Gy/25 fr) [13]. Boost dose improved local control (local failure 7.3 vs. $15.1 \%)$, especially in younger patients with positive surgical margins and a high proliferation index. A non-significant decrease in physician-based cosmetic results was observed in the boost arm and a higher rate of fat necrosis [13]. The St. George and Wollongong (SGW) trial randomized 688 breast cancer patients to receive conventionally fractionated WBRT ( $50 \mathrm{~Gy} / 25 \mathrm{fr}$ ) with no boost vs. lower dose WBRT (45 Gy/25 fr) and a sequential boost of $16 \mathrm{~Gy} / 8$ fr delivered with electrons [14]. In the 6-year analysis, no difference in terms of local control could be detected between treatment arms [15]. Nevertheless, the boost arm had improved overall cosmetic results as assessed by an external expert panel (79 vs. $68 \%$; p $=0.016$ ) and a lower (not statistically significant) breast retraction assessment score, maybe due to the reduced whole-breast dose [14]. However, generally, the application of a tumor bed boost dose is recommended for patients below the age of 40 having a large tumor, close surgical margins, high-grade invasive or in situ ductal tumors, a high proliferation index, hormone receptor-negative tumors, and an extensive intraductal component [2].

\section{How to Fit with Hypofractionation}

The administration of daily doses higher than 1.8-2 Gy using HF is a common option for WBRT after BCS for early breast cancer [16]. HF has been used in several institutions for decades and tested in randomized controlled trials (RCTs) [17]. In the United
Kingdom, comprehensive guidelines by the National Institute of Clinical Excellence (NICE) on the management of early breast cancer recommend HF (40 Gy/15 fr) as the standard solution [18]. Potential advantages of HF are directed at patients (convenience and costs), radiotherapy departments (patients turnover), and global health systems (costs) [9]. The American Society for Radiation Oncology (ASTRO) recommends the use of HF to deliver WBRT for patients with the following features: early breast cancer, age $\geq 50$ years, stage pT1-pT2, dose homogeneity within $\pm 7 \%$ in the central axis plane of the treatment plan, and being chemotherapy-naïve [19]. 4 large phase III RCTs investigated the role of HF versus conventional fractionation ( $50 \mathrm{~Gy} / 25$ fr over 5 weeks) in terms of local recurrence rate, side effects, and cosmetic results. The RMH/GOC trial randomized 1,410 patients with T1-T3/N0-N1 (after clearmargins BCS) to 3 different WBRT schedules delivered over 5 weeks: conventional fractionation vs. $39 \mathrm{~Gy} / 13 \mathrm{fr}$ (3 Gy daily) and $42.9 \mathrm{~Gy} / 13 \mathrm{fr}$ (3.3 Gy/day). In this study, $75 \%$ of patients received a direct electron field boost dose to the tumor bed (14 Gy/7 fr) [20]. The multi-institutional START A trial enrolled 2,236 women with a trial design similar to RMH/GOC except for a decreased daily dose (3.2-41.6 Gy/13 fr) in the second experimental arm. In this study, $60.6 \%$ of patients received an extra dose to the tumor bed [21]. The START B trial accrued 2,215 patients with the same eligibility criteria as START A. The experimental arm accelerated treatment with $40 \mathrm{~Gy} / 15$ fr over 3 weeks. Only $42.6 \%$ of patients received a boost dose [22]. Finally, the Canadian trial, updated with a median follow-up of 10 years, randomized T1-T2 nodenegative breast cancer patients with negative margins to receive $42.5 \mathrm{~Gy} / 16$ fr over 3.5 weeks or standard fractionation, without any boost dose [23]. None of the 4 RCTs explored the use of the boost dose to the tumor bed within their treatment protocol. The Canadian trial had no boost. The UK trials delivered a conventionally fractionated boost dose sequential to WBRT, at the institution's discretion, with a 1-2-week increase in overall treatment time. Thus, no definitive conclusions may be drawn from these trials about the ideal integration of tumor bed boost and WBRT whenever HF is employed. Table 1 shows an overview of clinical data on HF trials.

\section{Why Integration with WBRT Might Work}

At present, the optimal hypofractionted WBRT regimen to be delivered whenever a boost to the tumor bed is planned has not yet been determined; neither has the optimal tumor bed boost dose and fractionation to be adopted in conjunction with WBRT schedules employing HF. Finally, the timing of the combination, concomitant or sequential, has yet to be established. The incorporation of the boost dose within WBRT, with concurrent delivery, concomitant boost, or simultaneous integrated boost (SIB) increases the time-saving benefit of HF in the WBRT phase, further reducing overall treatment time. Moreover, the incorporation of the boost within the whole breast phase provides a dosimetric advantage towards both organs at risk and target volumes. Several dosimetric 
Table 1. Phase III trials investigating hypofractionated whole breast radiotherapy in breast cancer

\begin{tabular}{|c|c|c|c|c|c|c|}
\hline Study [ref.] & Country & Patients, $\mathrm{n}$ & $\begin{array}{l}\text { Dose/ } \\
\text { fractionation }\end{array}$ & $\begin{array}{l}\text { Patients receiving } \\
\text { boost dose, \% }\end{array}$ & $\begin{array}{l}\text { Median observation } \\
\text { time, years }\end{array}$ & $\begin{array}{l}\text { Local relapse } \\
\text { rate, } \%\end{array}$ \\
\hline \multirow[t]{2}{*}{$\begin{array}{r}\text { OCOG } \\
{[23]}\end{array}$} & \multirow[t]{2}{*}{ Canada } & 612 & $\begin{array}{l}50 \mathrm{~Gy} / 25 \mathrm{fr} \\
\text { (2 Gy daily) }\end{array}$ & 0 & \multirow[t]{2}{*}{10} & 6.7 \\
\hline & & 622 & $\begin{array}{l}42.5 \mathrm{~Gy} / 16 \mathrm{fr} \\
\text { (2.65 Gy daily) }\end{array}$ & 0 & & 6.2 \\
\hline \multirow[t]{3}{*}{$\begin{array}{c}\mathrm{RMH} / \mathrm{GOC} \\
{[48]}\end{array}$} & \multirow[t]{3}{*}{ UK } & 470 & $\begin{array}{l}50 \text { Gy/25 fr } \\
\text { (2 Gy daily) }\end{array}$ & 74 & \multirow[t]{3}{*}{10} & 12.1 \\
\hline & & 466 & $\begin{array}{l}42.9 \text { Gy/13 fr } \\
\text { (3.3 Gy daily) }\end{array}$ & 75 & & 9.6 \\
\hline & & 474 & $\begin{array}{l}39 \mathrm{~Gy} / 13 \mathrm{fr} \\
\text { (3 Gy daily) }\end{array}$ & 74 & & 14.4 \\
\hline \multirow[t]{3}{*}{$\begin{array}{c}\text { START A } \\
{[21]}\end{array}$} & \multirow[t]{3}{*}{ UK } & 749 & $\begin{array}{l}50 \mathrm{~Gy} / 25 \mathrm{fr} \\
\text { (2 Gy daily) }\end{array}$ & 60 & \multirow[t]{3}{*}{5} & 3.6 \\
\hline & & 750 & $\begin{array}{l}41.6 \mathrm{~Gy} / 13 \mathrm{fr} \\
\text { (3.2 Gy daily) }\end{array}$ & 61 & & 3.5 \\
\hline & & 737 & $\begin{array}{l}39 \mathrm{~Gy} / 13 \mathrm{fr} \\
\text { (3 Gy daily) }\end{array}$ & 61 & & 5.2 \\
\hline \multirow[t]{2}{*}{$\begin{array}{c}\text { START B } \\
\text { [22] }\end{array}$} & \multirow[t]{2}{*}{ UK } & 1,105 & $\begin{array}{l}50 \mathrm{~Gy} / 25 \mathrm{fr} \\
\text { (2 Gy daily) }\end{array}$ & 41 & \multirow[t]{2}{*}{10} & 5.5 \\
\hline & & 1,110 & $\begin{array}{l}40.05 \mathrm{~Gy} / 15 \mathrm{fr} \\
\text { (2.67 Gy daily) }\end{array}$ & 44 & & 4.3 \\
\hline
\end{tabular}

$\mathrm{fr}=$ Fractions.

comparison planning studies investigated the potential advantage of boost integration. Singla et al. [24] compared SIB plans using intensity-modulated radiation therapy (IMRT) vs. 3D conformal RT to deliver a 16 Gy tumor bed SIB above 50.4 Gy of conventionally fractionated WBRT. An improvement in target conformity (up to $67 \%$ ) could be detected with IMRT SIB as a reduction in mean lung dose (MLD) and maximum heart dose. Hurkmans et al. [25] performed a planning study of SIB using inverse optimization vs. a 3 -field boost approach. The comparison demonstrated similar volume of whole breast and tumor bed receiving $>95 \%$ of the prescribed dose and a similar mean heart dose (MHD) and MLD. Interestingly, the SIB approach provided better conformity and a reduction in the volume of whole breast (excluding the boost volume) receiving $>95 \%$ of the prescribed dose. This is in line with other findings. Van der Laan et al. [26] reported on a comparative planning study of SIB in 30 patients affected by left-sided breast cancer, comparing standard RT (50 Gy/25 fr + $16 \mathrm{~Gy} / 8 \mathrm{fr}$ ) as a sequential boost vs. a forward-planned 3D conformal WBRT delivering $1.81 \mathrm{~Gy} \times 28$ fr with a concomitant boost of 0.49 Gy (2.3 daily). With boost incorporation, the mean volume of whole breast getting $\geq 107 \%$ of the prescribed dose was reduced by $20 \%$, the mean volume of breast tissue outside the tumor bed receiving $\geq 95 \%$ of the boost dose was reduced by $54 \%$, and MHD and MLD were reduced by $10 \%$. Consistently, in a comparison between $3 \mathrm{D}$ conformal RT and helical tomotherapy for WBRT, Hijal et al. [27] demonstrated that a tomotherapy-based SIB approach leads to a reduction in excess irradiation of the whole breast excluding the tumor bed. With the 3D conformal technique, a large amount of breast tissue outside the tumor bed was untimely irradiated. This issue has clinical implications. Interestingly, Franco et al. [28], using static ports of tomotherapy for conventionally fractionated WBRT (50 Gy/25 fr) and a sequential boost (10-16 Gy/5-8 fr) delivered with helical tomotherapy, demonstrated that the adjunctive dose received by the whole breast volume minus the tumor bed volume $\left(\mathrm{V}_{52,5 \mathrm{~Gy}}, \mathrm{~V}_{55 \mathrm{~Gy}}, \mathrm{~V} 57.5 \mathrm{~Gy}\right)$ was correlated with G2-G3 acute skin toxicity [28]. In that cohort of 120 patients, more than $1 / 3$ of the whole breast received $105 \%$ of the prescribed dose, almost $1 / 5$ received $110 \%$, and more than $1 / 10$ received $115 \%$, due to the sequential boost phase. In a subsequent phase II trial, Franco et al. [29] employed a static angle tomotherapy approach to deliver hypofractionated SIB WBRT achieving consistent dosimetric results as $\mathrm{V}_{105 \%}$ (for whole breast planning target volume (PTV) minus tumor bed PTV) was very low $(2.4 \pm 0.9)$ and $\mathrm{V}_{110 \%}$ negligible (0.01), strongly limiting unintended irradiation outside the tumor bed. These dosimetric results were reflected by a robust reduction in acute skin toxicity. Figure 1 shows beam arrangements, dose distributions, and consequent dose-volume histograms of right-sided (fig. 1a) and left-sided (fig. 1b) breast cancer treated with hypofractionated WBRT, employing a SIB approach to the tumor bed delivered with static ports of tomotherapy.

\section{Clinical Data on Concurrent Boost}

Several mono-institutional prospective or retrospective studies provided clinical data on boost integration during WBRT. Recently, a German multicenter study (ARO-2010-01) reported the feasibility and adherence to dose constraints of a SIB schedule in early breast cancer patients after BCS (40 Gy/16 fr, 2.5 Gy daily as WBRT; 48 Gy/16 fr, 3 Gy/16 fr to the tumor bed) [30]. Freedman et 
Fig. 1. Examples of hypofractionation and simultaneous integrated boost (SIB) delivered with static ports of tomotherapy (a right- and $\mathbf{b}$ left-sided breast cancer).
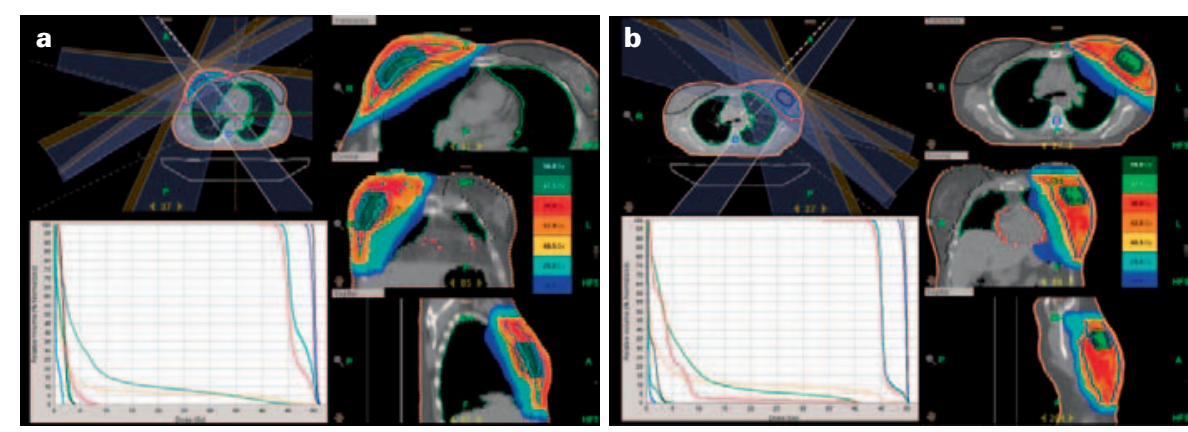

al. [31] (Fox Chase Cancer Center) enrolled 75 patients (Tis-T2 breast cancer with clear resection margins) into a phase II trial of photon-based WBRT delivered over 4 weeks up to $45 \mathrm{~Gy} / 20 \mathrm{fr}$ ( 2.25 Gy daily) with an IMRT incorporated boost of 2.8 Gy daily to $56 \mathrm{~Gy} / 20$ fr. 5-year local control was 97.3\%. Cosmetic outcome, evaluated using a patient- and physician-reported Breast Cancer Treatment Outcome Scale (BCTOS), was close to excellent with minimal difference between treated and untreated breasts. Chadha et al. [32] (Beth Israel Medical Center) treated 160 early breast cancer patients (Tis-T2, node-negative, negative resection margins, and chemotherapy-naïe) with accelerated HF RT delivering 40.5 Gy/15 fr (2.7 Gy daily) to the whole breast (over 3 weeks; 19 days) with an adjunctive concurrent 0.3 Gy daily to the tumor bed, to 45 Gy/15 fr. With a median follow-up of 3.5 years, the 5-year OS and disease-free survival (DFS) were 90 and 97\%, respectively; local control was $99 \%$. No late toxicity higher than G2 according to the LENT-SOMA scale was observed among patients with $>2$ years follow-up. Formenti et al. [33] (NYU) enrolled 91 women into a single-arm prospective study of WBRT in prone position to 40.5 Gy/15 fr (2.7 Gy daily) over 3 weeks. A SIB was delivered to the tumor bed with IMRT to receive $45 \mathrm{~Gy} / 15 \mathrm{fr}$ (3 Gy daily; adjunctive 0.3 Gy daily). With a median follow-up of 12 months, 1 recurrence, 2 acute grade 3 toxicities according to RTOG/EORTC (reversible grade $1-2$ dermatitis in $67 \%$ of patients), and no grade 3 late effects according to LENT-SOMA were observed (grade 1 fibrosis in $48 \%$ of patients; grade 2 in 3\%). McDonald et al. [34] reported the 3-year outcome of a retrospective series of 354 patients (stage I-III disease, mostly free margins; node positivity allowed) treated with IMRT SIB consisting of 45 Gy/25 fr (1.8 Gy daily) to the whole breast and 2.14 Gy each day to the tumor bed concurrently, followed by a dedicated cavity boost of another 3 fr ( 2.14 Gy) to 59.92 Gy. Grade 3 acute toxicity was < 1\%, 3-year locoregional recurrence was $2.8 \%$ (among invasive breast cancers), and global cosmetic outcome was good to excellent in $96.5 \%$. BantemaJoppe et al. [35] treated, between 2005 and 2010, 940 patients with standard fractionated WBRT (50.4 Gy/28 fr; 1.8 Gy daily) and a SIB regimen to the tumor bed (2.3-2.4 Gy daily up to 64.4-67.2 Gy). 3-year locoregional control, recurrence-free survival, and OS rates were 99.2, 95.5, and 97.1\%, respectively. 5-year local control was $98.9 \%$ [36]. Regarding toxicity and cosmetic outcome, after a median follow-up time of 30 months (range 6-54 months), $8.5 \%$ of patients had $\geq$ G2 fibrosis in the boost area, chest wall pain was detected in 6.7\%, and teleangiectasia was detected in $3.7 \%$ ( $\geq$ G2) [37]. Half of the patients developed all-grade fibrosis outside the tumor bed. Finally, Cante et al. [38, 39] reported data on HF and concomitant boost with a schedule consisting of $45 \mathrm{~Gy} / 20 \mathrm{fr}$ delivered to the whole breast (2.25 daily) and an adjunctive $0.25 \mathrm{~Gy}$ daily dose to the tumor bed to a total nominal dose of $50 \mathrm{~Gy}(2.5$ Gy daily). The whole course was given over 4 weeks (26 days). After a median follow-up of 60 months, outcomes were consistent (OS 97.6\%; cancer-specific survival 99.4\%; DFS 96.6\%; local control 100\%). Cosmetic outcome was scored as excellent/good in $95.7 \%$ of patients. Selected mono-arm clinical series are presented in table 2.

\section{Ongoing Trials with Boost Integration}

Few prospective studies are presently investigating the role of boost integration during WBRT employing HF. The RTOG 1005 trial is a phase III prospective trial investigating accelerated WBRT for early breast cancer, comparing standard RT (50 Gy/25 fr) (with HF option of 42.7/16 fr; 2.67 Gy daily) followed by a sequential boost of 12-14 Gy/6-7 fr vs. a hypofractionated accelerated WBRT schedule of $40 \mathrm{~Gy} / 15 \mathrm{fr}$ (2.67 Gy daily) with a concomitant boost of 3.2 Gy to the tumor bed (up to $48 \mathrm{~Gy} / 15 \mathrm{fr}$ ). This trial has been recently closed to accrual, and results are eagerly awaited [40]. The IMPORT High trial tests dose-escalated RT delivered with IMRT in early breast cancer patients with higher than average risk of local recurrence, with the primary endpoint of palpable induration inside the boost volume of the irradiated breast [41]. The standard arm comprises $40.5 \mathrm{~Gy} / 15 \mathrm{fr}$ (2.7 Gy daily) and a sequential tumor bed boost of $16 \mathrm{~Gy} / 8 \mathrm{fr}$ for an extra 1.6 weeks ( 23 fractions for total of 4.6 weeks). 2 different experimental arms were chosen: in addition to $2.4 \mathrm{~Gy} \times 15 \mathrm{fr}$ to the whole breast and $2.67 \mathrm{~Gy} \times 15$ fr to the index quadrant, the first arm receives $3.2 \mathrm{~Gy} \times 15 \mathrm{fr}$ (up to $48 \mathrm{~Gy}$ ), while the second arm receives $3.53 \mathrm{~Gy} \times 15 \mathrm{fr}$ (up to $53 \mathrm{~Gy}$ ) to the tumor bed. These schedules were calculated (considering an $\alpha / \beta$ ratio $=3 \mathrm{~Gy}$ for tumor control) as isoeffective to $60 \mathrm{~Gy}$ and $69 \mathrm{~Gy}$, respectively. The global sample size is 2,568 patients: to date $61 \%$ have been accrued and the closure date is planned for next year (April 2015) [42]. The German IMRT-MC2 is a prospective, 2-armed (251 patients in each arm), multicenter, randomized phase III 
Table 2. Selected clinical series testing hypofractionation and a concomitant tumor bed boost in breast cancer radiotherapy
Table 3. Prospective phase III trials testing hypofractionation and concomitant boost for breast cancer radiotherapy

\begin{tabular}{|c|c|c|c|c|c|c|}
\hline Study [ref.] & Country & Patients, $\mathrm{n}$ & $\begin{array}{l}\text { Whole breast } \\
\text { fractionation }\end{array}$ & Boost fractionation & $\begin{array}{l}\text { Observation time, } \\
\text { years }\end{array}$ & $\begin{array}{l}\text { In-breast failure } \\
\text { rate, \% }\end{array}$ \\
\hline $\begin{array}{c}\text { Corvo et al. } \\
\text { [49] }\end{array}$ & Italy & 377 & $\begin{array}{l}46 \text { Gy/20 fr } \\
\text { (2.3 Gy daily) }\end{array}$ & $\begin{array}{l}1.2 \text { Gy weekly over } \\
\text { WBRT }\end{array}$ & 3 & 0 \\
\hline $\begin{array}{c}\text { Cante et al. } \\
\text { [39] }\end{array}$ & Italy & 375 & $\begin{array}{l}45 \mathrm{~Gy} / 20 \mathrm{fr} \\
\text { (2.25 Gy daily) }\end{array}$ & $\begin{array}{l}50 \mathrm{~Gy} / 20 \mathrm{fr} \\
(2.5 \mathrm{~Gy} \text { daily })\end{array}$ & 5 & 0 \\
\hline \multirow[t]{2}{*}{$\begin{array}{l}\text { Morganti et al. } \\
\text { [50] }\end{array}$} & Italy & 201 & $\begin{array}{l}40 \text { Gy/16 fr } \\
\text { (2.5 Gy daily) }\end{array}$ & $\begin{array}{l}44 \text { Gy/16 fr } \\
\text { (2.75 Gy daily) }\end{array}$ & 2.6 & 0 \\
\hline & & & $\begin{array}{l}50 \text { Gy/25 fr } \\
\text { (2 Gy daily) }\end{array}$ & $\begin{array}{l}60 \mathrm{~Gy} / 25 \mathrm{fr} \\
\text { (2.4 Gy daily) }\end{array}$ & & \\
\hline $\begin{array}{l}\text { Formenti et al. } \\
\text { [51] }\end{array}$ & USA & 91 & $\begin{array}{l}40.5 \mathrm{~Gy} / 15 \mathrm{fr} \\
\text { (2.7 Gy daily) }\end{array}$ & $\begin{array}{l}48 \mathrm{~Gy} / 15 \mathrm{fr} \\
\text { (3.2 Gy daily) }\end{array}$ & 1 & 0 \\
\hline $\begin{array}{l}\text { Freedman et al. } \\
\quad[31]\end{array}$ & USA & 75 & $\begin{array}{l}45 \mathrm{~Gy} / 20 \mathrm{fr} \\
(2.25 \mathrm{~Gy} \text { daily })\end{array}$ & $\begin{array}{l}58 \mathrm{~Gy} / 20 \mathrm{fr} \\
(2.8 \mathrm{~Gy} \text { daily })\end{array}$ & 5.8 & 2.7 \\
\hline
\end{tabular}

$\mathrm{fr}=$ Fractions; $\mathrm{WBRT}=$ whole breast radiotherapy.

\begin{tabular}{|c|c|c|c|c|c|c|}
\hline \multirow[t]{2}{*}{ Study [ref.] } & \multirow[t]{2}{*}{ Country } & \multirow[t]{2}{*}{ Primary endpoint } & \multirow{2}{*}{$\begin{array}{l}\text { Target } \\
\text { population, } \mathrm{n}\end{array}$} & \multicolumn{3}{|c|}{ Dose and fractionation (experimental arm) } \\
\hline & & & & whole breast & index quadrant & tumor bed \\
\hline $\begin{array}{l}\text { RTOG } 1005 \\
\quad[40]\end{array}$ & USA & in-breast relapse & 2,300 & $\begin{array}{l}40.05 \text { Gy/15 fr } \\
\text { (2.67 Gy daily) }\end{array}$ & l & $\begin{array}{l}48 \text { Gy/15 fr } \\
\text { (3.2 Gy daily) }\end{array}$ \\
\hline $\begin{array}{l}\text { IMPORT- } \\
\text { HIGH [42] }\end{array}$ & UK & palpable induration & 2,568 & $\begin{array}{l}36 \mathrm{~Gy} / 15 \mathrm{fr} \\
\text { (2.4 Gy daily) }\end{array}$ & $\begin{array}{l}40.05 \text { Gy/ } 15 \text { fr } \\
\text { (2.67 Gy daily) }\end{array}$ & $\begin{array}{l}\text { I: } 48 \text { Gy/15 fr } \\
\text { (3.2 Gy daily) } \\
\text { II: } 53 \text { Gy/15 fr } \\
\text { (3.53 Gy daily) }\end{array}$ \\
\hline $\begin{array}{l}\text { IMRT MC-2 } \\
\text { [43] }\end{array}$ & Germany & cosmetic outcome & 502 & $\begin{array}{l}50.4 \text { Gy/28 fr } \\
\text { (1.8 Gy daily) }\end{array}$ & l & $\begin{array}{l}64.4 \text { Gy/28 fr } \\
\text { (2.3 Gy daily) }\end{array}$ \\
\hline $\begin{array}{c}\text { UZB trial } \\
\text { [44] }\end{array}$ & Belgium & $\begin{array}{l}\text { pulmonary/cardiac } \\
\text { function } \\
\text { arm mobility and } \\
\text { lymphedema }\end{array}$ & 123 & $\begin{array}{l}42 \text { Gy/15 fr } \\
\text { (2.8 Gy daily) }\end{array}$ & l & $\begin{array}{l}51 / 15 \text { fr } \\
\text { (3.4 Gy daily) }\end{array}$ \\
\hline
\end{tabular}

$\mathrm{fr}=$ Fractions trial (primary endpoints: cosmetic outcome at 6 weeks and 2 years, and 2-year and 5-year local control) comparing an experimental arm of conventionally fractionated WBRT up to 50.4 Gy/28 fr (1.8 Gy daily) with an integrated boost of $64.4 \mathrm{~Gy} / 28 \mathrm{fr}$ (2.3 Gy daily) vs. a conventional arm employing WBRT of up to $50.4 \mathrm{~Gy} / 28 \mathrm{fr}$ (1.8 Gy daily) and a sequential boost of $16 \mathrm{~Gy} / 8 \mathrm{fr}$ (up to $66.4 \mathrm{~Gy}$ ) for a total of 36 fractions [43]. Finally, the UZ in Brussels performed a unicenter, non-blinded, randomized trial comparing conventional WBRT (50 Gy/25 fr) and a sequential boost of $16 \mathrm{~Gy} / 8 \mathrm{fr}$ for a total of $66 \mathrm{~Gy}$ over 7 weeks vs. an experimental arm of $42 \mathrm{~Gy} / 15 \mathrm{fr}$ ( 2.8 Gy daily) for WBRT with a SIB of 0.6 Gy daily (up to $51 \mathrm{~Gy} / 15$ fr over 3 weeks). Treatments were delivered with tomotherapy, and nodal areas and post-mastectomy patients (who did not receive a boost dose) were included [44]. The short-term toxicity profile was comparable between treatment arms. All these trial will provide evidence on boost integration during WBRT after BCS for early breast cancer. Table 3 summarizes the main characteristics of the available trials.

\section{Final Remarks}

The incorporation of the boost dose within either a conventionally fractionated or hypofractionated whole breast phase is definitely an interesting and promising field for clinical investigation [45]. It allows for treatment acceleration and dose escalation in the area of higher risk of relapse. Precise and reliable treatment techniques are mandatory to provide robust dosimetry, accurate delivery, and consistent clinical results. Patients should preferably be enrolled into clinical trials in order to have prospectively collected outcomes in terms of local control, long-term toxicity profile, cosmetic result, and quality of life [46, 47].

\section{Disclosure Statement}

The authors disclose no conflict of interest. 


\section{References}

1 Poortmans P: Evidence based radiation oncology: breast cancer. Radiother Oncol 2007;84:84-101.

2 Graham P, Fourquet A: Placing the boost in the breast conservation radiotherapy: a review of the role, indications and techniques for breast boost radiotherapy. Clin Oncol (R Coll Radiol) 2006;18:210-219.

3 Freedman GM, White J, Arthur DW, et al.: Accelerated fractionation with a concurrent boost for early stage breast cancer. Radiother Oncol 2013;106:15-20.

4 Early Breast Cancer Trialists' Collaborative Group: Effects of radiotherapy and of differences in the extent of surgery for early breast cancer on local recurrence and 15-year survival: an overview of the randomized trials. Lancet 2005;366:2087-2106.

5 Denham JW: The radiation dose-response relationship for control of primary breast cancer. Radiother Oncol 1986;7:107-123.

6 Holland R, Connolly JL, Gelman R, et al.: The presence of an extensive intraductal component (EIC) following a limited excision predicts for prominent residual disease in the remainder of the breast. J Clin Oncol 1990;8:113-118.

7 Freedman GM, Anderson PR, Hanlon AL, et al.: Pattern of local recurrence after conservative surgery and whole-breast irradiation. Int J Radiat Oncol Biol Phys 2005;61:1328-1336.

8 Polednack AP: Trends in, and predictors of, breastconserving surgery and radiotherapy for breast cancer in Connecticut, 1988-1997. Int J Radiat Oncol Biol Phys 2002;53:157-63.

9 Lievens Y: Hypofractionated breast radiotherapy: financial and economic consequences. Breast 2010;19:192-7.

10 Bartelink H, Horiot J-C, Poortmans P, et al.; European Organization for Research and Treatment of Cancer Radiotherapy and Breast Cancer Groups: Recurrence rates after treatment of breast cancer with standard radiotherapy with or without additional radiation. $\mathrm{N}$ Engl J Med 2001;345:1378-1387.

11 Bartelink H, Horiot J-C, Poortmans P, et al.: Impact of higher radiation dose on local control, survival in breastconserving therapy of early breast cancer: 10 years results of the randomized boost versus no boost EORTC trial 22881-10882. J Clin Oncol 2007;25:3259-3265.

12 Romestaing P, Lehingue Y, Carrie C, et al.: Role of a 10 -Gy boost in the conservative treatment of early breast cancer: results of a randomized clinical trial in Lyon, France. J Clin Oncol 1997;15:963-968.

13 Polgar C, Fodor J, Orosz Z, et al.: Electron and highdose rate brachytherapy boost in the conservative treatment of stage I-II breast cancer. First results of the randomized Budapest Boost Trial. Strahelenther Onkol 2002;178:615-623.

14 Hau E, Browne LH, Khanna S, et al.: Radiotherapy breast boost with reduced whole-breast dose is associated with improved cosmesis: the results of a comprehensive assessment for the St. George and Wollongong randomized breast boost trial. Int J Radiat Oncol Biol Phys 2012;82:682-689.

15 Graham P, Browne LH, Capp A, et al.: The St George Wollongong and Liverpool Breast boost trial: 1st planned analysis at 6 year median follow-up. Australasian Radiology 2007;51(suppl 3):A85.

16 Coles CE, Brunt AM, Wheatley D, et al.: Breast radiotherapy: Less is more?. Clin Oncol 2013;25:127-134.

17 Holloway CL, Panet-Raymond V, Olivotto I: Hypofractionation should be the new 'standard' for radiation therapy after breast conserving surgery. Breast 2010:19: 163-167.

18 Harnett A: Fewer fractions of adjuvant external beam radiotherapy for early breast cancer are safe and effective and can now be the standard of care. Why the UK's NICE accepts fewer fractions as the standard of care for adjuvant radiotherapy in early breast cancer. Breast 2010;19:159-162
Smith BD, Bentzen SM, Correa CR, et al.: Fractionation for whole breast irradiation: an American Society for Radiation Oncology (ASTRO) evidence-based guidelines. Int J Radiat Oncol Biol Phys 2011;81:59-68.

20 Yarnold J, Ashton A, Bliss J, et al.: Fractionation sensitivity and dose response of late adverse effects in the breast after radiotherapy for early breast cancer: long-term results of a randomized trial. Radiother Oncol 2005;75:9-17.

21 Bentzen SM, Agrawal RK, Aird EG, et al.; The START Trialists' Group: The UK Standardisation of Breast Radiotherapy (START) Trial A of radiotherapy hypofractionation for treatment of early breast cancer: a randomized trial. Lancet Oncol 2008;9:331-341.

22 Haviland JS, Owen JR, Dewar JA, et al.: The UK Standardisation of Breast Radiotherapy (START) Trials of radiotherapy hypofractionation for treatment of early breast cancer: 10-year follow-up results of two randomized trials. Lancet Oncol 2013;14:1086-1094.

23 Whelan TJ, Pignol JP, Levine MN, et al.: Long-term results of hypofractionated radiation therapy for breast cancer. N Engl J Med 2010;362:513-520.

24 Singla R, King S, Abuquerque K, et al.: Simultaneousintegrated boost intensity-modulated radiation therapy (SIB-IMRT) in the treatment of early-stage left-sided breast carcinoma. Med Dosim 2006;31:190-196.

25 Hurkmans CW, Meijer GJ, van-Vliet-Vroegindeweij, et al.: High-dose simultaneously integrated breast boost using intensity-modulated radiotherapy and inverse optimization. Int J Radiat Oncol Biol Phys 2006;66:923-930.

26 Van der Laan HP, Dolsma WV, Maduro JH, et al.: Three dimensional conformal simultaneously integrated boost technique for breast-conserving radiotherapy. Int J Radiat Oncol Biol Phys 2007;68:1018-1023.

27 Hijal T, Fourniez-Bodoz N, Castro-Pena P, et al.: Simultaneous integrated boost in breast conserving treatment of the breast: a dosimetric comparison of helical and three-dimensional conformal radiotherapy. Radiother Oncol 2010;94:300-306.

28 Franco P, Zeverino M, Migliaccio F, et al.: Intensity-modulated adjuvant whole breast radiation delivered with static angle tomotherapy (TomoDirect): a prospective case series. J Cancer Res Clin Oncol 2013;139:1927-1936.

29 Franco P, Zeverino M, Migliaccio F, et al.: Intensitymodulated and hypofractionated simultaneous integrated boost adjuvant breast radiation employing statics ports of tomotherapy (TomoDirect): a prospective phase II trial. J Cancer Res Clin Oncol 2014;140:167-177.

30 Dellas K, Vonthein R, Zimmer J, et al.: Hypofractionation with simultaneous integrated boost for early breast cancer: results of the German multicentre phase II trial (ARO-2010-01). Strahlenther Onkol 2014;190:646-653.

31 Freedman GM, Anderson PR, Bleicher RJ, et al.: Fiveyear local control in a phase II study of hypofractionated intensity modulated radiation therapy with an incorporated boost for early stage breast cancer. Int J Radiat Oncol Biol Phys 2012;84:888-893.

32 Chadha M, Woode R, Sillanpaa J, et al.: Early-stage breast cancer treated with 3-week accelerated wholebreast radiation therapy and concomitant boost. Int J Radiat Oncol Biol Phys 2013;86:40-44.

33 Formenti SC, Gidea-Addeo D, Goldberg JD, et al.: Phase I-II trial of prone accelerated intensity modulated radiation therapy to the breast to optimally spare normal tissue. J Clin Oncol 2007;25:2236-2242.

34 McDonald MW, Godette KD, Whitaker DJ, et al.: Three-year outcomes of breast intensity-modulated radiation therapy with simultaneous integrated boost. Int J Radiat Oncol Biol Phys 2010;77:523-530.

35 Bantema-Joppe EJ, van der Laan HP, deBock GH, et al.: Three-dimensional conformal hypofractionated simultaneous integrated boost in breast conserving therapy: results on local control and survival. Radiother Oncol $2011 ; 100 ; 215-220$.
6 Bantema-Joppe EJ, Vredeveld EJ, deBock GH, et al. Five year outcome of hypofractionated simultaneous integrated boost irradiation in breast conserving therapy: patterns of recurrence. Radiother Oncol 2013;108: 269-272.

37 Bantema-Joppe EJ, Schilstra C, de Bock GH, et al.: Simultaneous integrated boost irradiation after breastconserving surgery: physician-rated toxicity and cosmetic outcome at 30 months' follow up. Int J Radiat Oncol Biol Phys 2012;83:e471-477.

38 Cante D, Rosa La Porta M, Casanova-Borca V, et al.: Accelerated hypofractionated adjuvant whole breast radiotherapy with concomitant photon boost after conserving surgery for early breast cancer: a prospective evaluation on 463 patients. Breast J 2011;17:586-593.

39 Cante D, Franco P, Sciacero P, et al.: Five-year results of a prospective case series of accelerated hypofractionated whole breast radiation with concomitant boost to the tumor bed after conserving surgery for early breast cancer. Med Oncol 2013;30:518.

40 RTOG 1005: A Phase III trial of accelerated whole breast irradiation with hypofractionation plus concurrent boost versus standard whole breast irradiation plus sequential boost for early-stage breast cancer. $w w w$. rtog.org, accessed March 3rd, 2014.

41 Coles C, Yarnold J; IMPORT Trials Management Group: The IMPORT trials are launched (September 2006). Clin Oncol 2006;18:587-590.

42 Import High trial. www.icr.ac.uk, accessed March 3rd, 2014.

43 Askoxylakis V, Jensen AD, Hafner MF, et al.: Simultaneous integrated boost for adjuvant treatment of breast cancer - intensity modulated vs. conventional radiotherapy: the IMRT-MC2 trial. BMC Cancer 2011;11:249.

44 Van Parijs H, Miedema G, Vinh-Hung V, et al.: Short course radiotherapy with simultaneous integrated boost for stage I-II breast cancer, early toxicities of a randomized trial. Radiat Oncol 2012;7:80.

45 Souchon R, Sautter-Bihl ML, Sedlmayer F, et al.; on behalf of the Breast Cancer Expert Panel of the German Society of Radiation Oncology (DEGRO): Radiation oncologists' view on the Zurich consensus. Breast Care (Basel) 2013;8:448-452.

46 Sedlmayer F, Sautter-Bihl ML, Budach W, et al.; Breast Cancer Panel of the German Society of Radiation Oncology (DEGRO): Is the simultaneously integrated boost (SIB) technique for early breast cancer ready to be adopted for routine adjuvant radiotherapy? Statement of the German and the Austrian Societies of Radiooncology (DEGRO/ÖGRO). Strahlenther Onkol 2013;189:193-196.

47 Untch M, Gerber B, Harbeck N, et al.: 13th St. Gallen International Breast Conference 2013: primary therapy for early breast cancer evidence, controversies, consensus - opinion of a German team of experts (Zurich 2013). Breast Care 2013;8:221-229.

48 Owen JR, Ashton A, Bliss JM, et al.: Effect of radiotherapy fraction size on tumor control in patients with early-stage breast cancer after local tumor excision: long-term results of a randomized trial. Lancet Oncol 2006;7:467-471.

49 Corvo R, Ricchetti F, Doino D, et al.: Adjuvant hypofractionated radiotherapy with weekly concomitant boost for women with early breast cancer: the clinical experience at Genoa university. Anticancer Res 2010; 30:4749-4753.

50 Morganti AG, Cilla S, Valentini V, et al.: Phase I-II studies on accelerated IMRT in breast carcinoma: technical comparison and acute toxicity in 332 patients. Radiother Oncol 2009;90:86-92.

51 Formenti SC, Gidea-Addeo D, Goldberg JD, et al. Phase I-II trial of prone accelerated intensity modulated radiation therapy to the breast to optimally spare normal tissue. J Clin Oncol 2007;25:2236-42. 